\title{
KANDUNGAN FRAKSI SERAT RANSUM PELLET UNGGAS DENGAN PENGGUNAAN TEPUNG indigoferazollingeriana
}

\author{
P.Z. JATI, T. ADELINA DAN D. A. MUCRA \\ Fakultas Pertanian dan Peternakan Universitas Islam Negeri Sultan Syarif Kasim Riau \\ Kampus II Raja Ali Haji Jln. Soebrantas KM 16 Panam-Pekanbaru \\ Email : putrizuliajati@yahoo.com
}

\begin{abstract}
This study aims to evaluation the effect of Indigofera zollingeriana flour utilization inpoultry pellet ration on the content of the fiber fraction ,namely : Neutral Detergent Fiber (NDF), Acid Detergent Fiber (ADF), Acid Detergent Lignin (ADL), hemicelluloses and cellulose. The experimental design used Completely Randomized Design(CRD),which consists of 4 treatments and 5 replicates. The treatments were the level of Indigofera zollingeriana flour utilization that were T0 $=0 \%$ Indigofera zollingeriana (control), $T 1=5 \%$ Indigofera zollingeriana, $T 2=10 \%$ Indigofera zollingeriana, $T 3=15 \%$ Indigofera zollingeriana. The results showed that the Indigofera zollingeriana utilization had no significant effect $(P>0.05)$ on the content of NDF, hemicellulose, cellulose but had significantly effect $(P<0.05)$ to the content of ADF and highly significant effect $(P<0.01)$ on the content of $A D L$. It was concluded that the use of $15 \%$ Indigofera zollingerian alowered the content ADF and $A D L$, unable to reduce the content fNDF and unable to increase the content of hemicellulose and cellulose.The use of $15 \%$ Indigofera zollingeriana is the best $30.39 \%$ NDF; $9.42 \%$ ADF; $2.25 \%$ ADL; $20.98 \%$ hemicellulose and $4.53 \%$ cellulose.
\end{abstract}

Keywords: Indigofera zollingeriana flour, poultry rations, fiber fraction, pellet.

\section{PENDAHULUAN}

Ketersediaan bahan utama pakan saat ini masih berasal dari bahan impor, dan di sisi lain distribusi pakan ternak komersil untuk ternak dari pabrik ke peternak mata rantainya sangat panjang, sehingga harga jual di tingkat sub agen atau penjual pakan menjadi mahal. Oleh sebab itu sangat diperlukan sumber bahan pakan alternatif yang mampu berproduksi dalam jumlah besar, murah, tidak bersaing dengan kebutuhan manusia namun memiliki kualitas yang baik dan mengandung nutrisi yang tinggi sehingga mampu menjamin kontinuitas pakan guna peningkatan produksi ternak.

Salah satu tanaman yang memiliki kandungan nutrisi yang tinggi dan juga tidak bersaing dengan kebutuhan manusia yaitu legum Indigofera zollingeriana, dimana tanaman ini bisa tumbuh pada tingkat kesuburan tanah yang rendah, ketersediaan air yang terbatas dan tahan terhadap genangan air sehingga tanaman ini mudah dalam perawatan.
Hassen et al., (2007) menyatakan legum Indigofera zollingeriana memiliki kandungan protein yang tinggi, toleran terhadap musim kering, genangan air dan tahan terhadap salinitas. Sehingga diasumsikan dapat menggantikan komposisi subtrat yang lain, yakni dedak sehingga kandungan NDF, ADF dan ADL menurun dan kandungan hemiselulosa dan selulosa dapat meningkat.

Salah satu alternatif pemanfaatan Indigofera zollingeriana sebagai pakan secara maksimal adalah dengan pengolahan secara mekanik yakni menjadi pakan pellet. Pengolahan hijauan Indigofera zollingeriana menghasilkan produk pelet daun murni (100\%) bernama Indigofeed (Abdullah, 2010), yang telah diuji daya simpan, daya kemudahan penanganan dan pabrikasinya (Izzah, 2011).

Menurut Ichwan (2003) manfaat pembuatan pakan dalam bentuk pellet dapat meningkatkan palatabilitas ternak dan setiap butiran pellet mengandung nutrisi yang sama, sehingga formula pakan 
menjadi efisien dan ternak tidak diberi kesempatan untuk memilih makanan yang disukai. Akbarillah dkk. (2010) menambahkan penggunaan tepung daun Indigofera zollingeriana $10 \%$ masih baik pengaruhnya terhadap produksi telur, berat telur dan perbaikan warna kuning telur.

\section{MATERI DAN METODE}

Penelitian pembuatan pellet dilakukan dilakukan di Laboratorium Agrostologi, Industri Pakan dan Ilmu Tanah Fakultas Pertanian dan Peternakan UIN Sultan Syarif Kasim Riau. Pembuatan tepung daun Indigofera zollingeriana dapat dilihat pada Gambar 1.

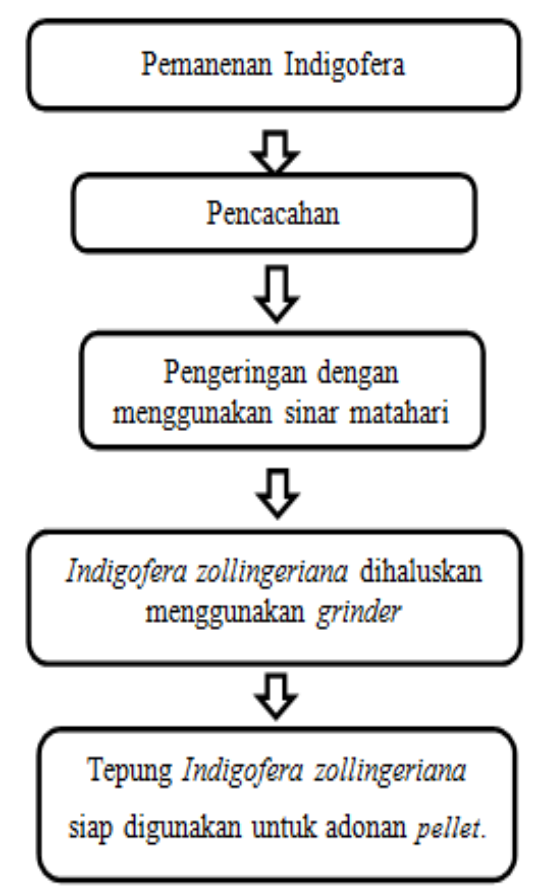

Gambar 1. Proses Pembuatan Tepung Indigofera zollingeria

Indigofera zolligeriana yang telah menjadi tepung (mash), selanjutnya bersama jagung halus, dedak halus, konsentrat komersial dicampur atau diaduk hingga merata (homogen) di dalam baskom dengan sendok pengaduk. Apabila bahan telah menjadi bentuk adonan, kemudian dilakukan pemeraman selama 1 hari, setelah itu ditambahkan putih telur dan diaduk hingga merata, selanjutnya adonan dimasukkan ke dalam mesin pellet untuk menghasilkan pakan berupa pellet dengan persentase yang berbeda sesuai tiap-tiap perlakuan. Adonan kemudian dicetak, selanjutnya dilakukan proses penggeringan pellet selama 3-5 jam menggunakan sinar matahari. Analisis fraksi serat dilakukan di Laboratorium Ilmu Nutrisi dan Kimia Fakultas Pertanian dan Peternakan UIN Suska Riau. Penelitian telah dilaksanakan pada bulan Desember 2015 - Januari 2016.

Rancangan percobaan yang digunakan ialah Rancangan Acak Lengkap (RAL) yang terdiri dari 4 perlakuan 5 ulangan yaitu :

$\mathrm{T} 0=$ Penggunaan $0 \%$ Indigofera zollingeriana (kontrol)

$\mathrm{T}_{1}=$ Penggunaan $5 \%$ Indigofera zollingeriana $\mathrm{T}_{2}=$ Penggunaan $10 \%$ Indigofera zollingeriana $\mathrm{T} 3=$ =Penggunaan $15 \%$ Indigofera zollingeriana

Komposisi bahan baku yang digunakan dalam penyusunan ransum dan susunan ransum penelitian disajikan padaTabel 1.dan 2. 
Tabel 1. Kandungan nutrisi bahan baku pakan (\%)

\begin{tabular}{llrrrrl}
\hline Sampel & BK & \multicolumn{1}{c}{ PK } & \multicolumn{1}{c}{ LK } & ABU & \multicolumn{1}{c}{ SK } & BETN \\
\hline Indigofera & 90,60 & 28,95 & 2,94 & 9,80 & 12,75 & 45,56 \\
Dedak & 92,61 & 8,58 & 10,75 & 13,77 & 21,57 & 45,33 \\
Jagung & 91,20 & 7,55 & 2,98 & 3,60 & 1,96 & 83,90 \\
Konsentrat & 92,80 & $39,09^{*}$ & 6,29 & 16,20 & 1,96 & 58,91 \\
\hline
\end{tabular}

Ket : Hasil Analisis Lab.Nutrisi Kimia UIN SUSKA (2016)

*Hasil Analisis Lab.Nutrisi Ikan Universitas Riau (2016)

Tabel 2. Kandungan nutrisi fraksi serat dedak halus dan Indigofera zollingeriana (\%)

\begin{tabular}{llllrl}
\hline Sampel & NDF & ADF & ADL & Hemiselulosa & Selulosa \\
\hline Indigofera & 36,11 & 26,34 & 7,72 & 9,76 & 17,24 \\
Dedak & 54,71 & 38,46 & 3,84 & 16,25 & 36,53
\end{tabular}

Ket : Hasil Analisis Lab.Nutrisi Kimia UIN SUSKA (2016)

Komposisi formulasi ransum penelitian disajikan untuk unggas petelur berdasarkan SNI, (2006) disajikan padaTabel 3.

Tabel 3. Formulasi ransum penelitian dan kandungan nutrisi perlakuan(\%)

\begin{tabular}{lcccc}
\hline \multicolumn{1}{c}{ Bahan Pakan } & \multicolumn{5}{c}{ Perlakuan } \\
\hline Dedak Halus & 25 & 20 & 15 & 10 \\
Jagung Halus & 45 & 45 & 45 & 45 \\
Konsentrat & 30 & 30 & 30 & 30 \\
Indigofera & - & 5 & 10 & 15 \\
\hline Total & 100 & 100 & 100 & 100 \\
\hline PK (\%) & 16,53 & 17,79 & 18,69 & 19,77 \\
SK (\%) & 3,04 & 3,70 & 4,36 & 5,02 \\
LK $(\%)$ & 4,99 & 5,12 & 5,24 & 5,36 \\
Ca (\%) & 0,22 & 0,23 & 0,24 & 0,24 \\
P(\%) & 0,01 & 0,02 & 0,03 & 0,03 \\
ME $(\mathrm{kkal} / \mathrm{Kg})$ & 2640,1 & 2652,5 & 2664,8 & 2677,2 \\
\hline
\end{tabular}

Peubah yang diukur yaitu komposisi fraksi serat yaitu : ADF, NDF, ADL, selulosa dan hemiselulosa. Data hasil percobaan yang diperoleh diolah menurut analisis keragaman Rancangan Acak Lengkap (RAL) menurut Steel dan Torrie (1991) dan apabila hasil analisis ragam menunjukkan pengaruh nyata maka dilakukan uji lanjut dengan Duncan's Multiple Range Test (DMRT).

\section{HASIL DAN PEMBAHASAN}

Rataan kandungan NDF, ADF, ADL, hemiselulosa dan selulosa pellet perlakuan penelitian dapat dilihat pada Tabel 4. 
Tabel 4. Rataan kandungan NDF, ADF, ADL, hemiselulosa dan selulosa (\%)

\begin{tabular}{lllllc}
\hline \multirow{2}{*}{ Perlakuan } & \multicolumn{5}{c}{ Rataan } \\
\cline { 2 - 5 } & NDF & ADF $^{*}$ & ADL $^{* *}$ & Hemiselulosa & Selulosa \\
\hline Penggunaan 0\% IZ & $31,01 \pm 4,28$ & $15,87^{\mathrm{b}} \pm 3,34$ & $6,40^{\mathrm{c}} \pm 0,93$ & $15,14 \pm 5,77$ & $6,78 \pm 1,66$ \\
Penggunaan 5\% IZ & $32,10 \pm 6,77$ & $14,40^{\mathrm{b}} \pm 1,22$ & $4,16^{\mathrm{b}} \pm 1,61$ & $17,69 \pm 5,72$ & $8,71 \pm 1,71$ \\
Penggunaan 10\% IZ & $30,47 \pm 5,99$ & $12,52^{\mathrm{a}} \pm 3,57$ & $3,42^{\mathrm{a}} \pm 1,62$ & $17,95 \pm 5,14$ & $7,19 \pm 3,31$ \\
Penggunaan 15\% IZ & $30,39 \pm 4,60$ & $9,42^{\mathrm{a}} \pm 2,61$ & $2,25^{\mathrm{a}} \pm 0,81$ & $20,98 \pm 3,97$ & $4,53 \pm 2,19$ \\
\hline
\end{tabular}

Ket : IZ : Indigofera zollingeriana

* : Superskrip berbeda pada kolom yang sama menunjukkan perbedaan nyata $(\mathrm{P}<0,05)$

** : Superskrip berbeda pada kolom yang sama menunjukkan perbedaan sangat nyata $(\mathrm{P}<0,01)$

\pm : Merupakan Standar Deviasi

\section{Kandungan ADF Pellet}

Rataan kandungan ADF pellet perlakuan penelitian dapat dilihat pada Tabel 4. Hasil analisis ragam memperlihatkan perlakuan penggunaan Indigofera zollingeriana sampai $15 \%$ memperlihatkan hasil yang signifikan menurunkan kandungan ADF pellet. Hasil analisis uji lanjut menunjukkan pengaruh yang nyata $(\mathrm{P}<0,05)$ penurunan kandungan ADF Pellet seiring dengan penggunaan Indigofera zollingeriana, dimana nilai ADF tertinggi pada $0 \%$ Indigofera zollingeriana dan ADF terendah pada $15 \%$ penggunaan Indigofera zollingeriana.

Penurunan kandungan ADF pellet hasil penelitian ini diduga karena selama proses pengepresan sampel dapat dikategorikan proses perlakuan fisik pada pembuatan pellet, dimana proses tersebut diduga dapat merubah kandunganADF menjadi rendah. Menurut pendapat Svihus dan Zimonja (2011) perlakuan pellet juga dapat merubah komposisi kimia dan fisik dari pakan.

Penurunan kandungan ADF pellet diduga berkaitan dengan peningkatan level Indigofera zollingeriana diiringi dengan menurunnya level dedak halus, dimana kandungan ADF dedak halus (38,46\%) lebih tinggi dibanding ADF Indigofera zollingeriana $(26,34 \%)$. Hal ini sesuai dengan hasil penelitian Maulidayanti (2015) yang menyatakan kandungan ADF silase pelepah sawit semakin menurun seiring penggunaan biomassa Indigofera zollingeriana (20\%, 40\% dan $60 \%)$. Selain itu diduga juga terdapat pengaruh kandungan fraksi serat yang terjadi selama pemeraman 1 hari, dimana pemeraman selama proses perlakuan diduga dapat merubah komposisi fraksi serat. Menurut Astuti dkk. (2011) semakin lama pemeraman semakin menurunkan kandungan fraksi serat, hal ini diduga terurainya isi sel pada saat diperam, semakin lama diperam semakin banyak isi sel yang terurai.

Kandungan ADF pellet dengan penggunaan Indigofera zollingeriana berkisar 9,42\%-15,87\%, kandungan ADF pada penelitian ini relatif sama dibandingkan dengan yang dilaporkan Yono dkk. (2002) pada pollard gandum terfermentasi dengan Aspergillus niger pada pakan unggas itik alabio dan mojosari terjadi penurunan kandungan fraksi serat yaitu ADF 10,48\%$13,32 \%$, sedangkan yang dilaporkan Maulidayanti (2015) kandungan ADF silase pelepah sawit yangditambah biomassa indigofera (Indigofera zollingeriana) lebih tinggi yaitu 33,50\%-56,22\%. 


\section{Kandungan ADL Pellet}

Rataan kandugan ADL pellet perlakuan penelitian dapat dilihat pada Tabel 4 . Hasil analisis ragam menunjukkan perlakuan penggunaan Indigofera zollingeriana sampai 15\% memperlihatkan hasil yang signifikan menurunkan kandungan ADL pellet. Hasil analisis uji lanjut menunjukkan terjadi perbedaan yang sangat nyata $(\mathrm{P}<0,01)$ terhadap penurunan kandungan ADL pellet seiring dengan penggunaan Indigofera zollingeriana, dimana nilai ADL tertinggi $(6,04 \%)$ pada $0 \%$ Indigofera zollingeriana dan ADL terendah $(2,25 \%)$ pada $15 \%$ penggunaan Indigofera zollingeriana.

Terjadinya penurunan kandungan ADL pellet diduga karena selama proses pembuatan pellet terjadi proses pengepresan (pelleting) yang diiringi dengan pemanasan saat pencetakan pellet serta pemanasan pada saat penjemuran pellet dimana proses tersebut dapat merubah kandungan ADL pellet menjadi lebih rendah. Hal ini didukung oleh Svihus dan Zimonja (2011) perlakuan pellet juga dapat merubah komposisi kimia dan fisik dari pakan.

Selain itu diduga karena adanya penggunaan bahan campuran lainnya dalam pellet yaitu dedak yang kandungannya menurun seiring dengan penggunaan Indigofera zollingeriana, ini menyebabkan komposisi substrat menurunkan ADL dimana kandungan ADL dedak 3,84\% (Tabel 2.) dan kandungan ADL Indigofera zollingeriana 7,72\% (Tabel 3.2). Penurunan kandungan ADL pada penggunaan Indigofera zollingeriana diduga juga berkaitan dengan kandungan ADF hasil penelitian pada (Tabel 4.) sehingga diasumsikan apabila ADF mengalami penurunan maka kandungan ADL juga diperkirakan akan menurun. Maulidayanti (2015) menambahkan kandungan ADF silase pelepah sawit semakin menurun seiring penggunaan biomassa Indigofera zollingeriana $(20 \%, 40 \%$ dan $60 \%)$ ini berkaitan dengan penurunan ADL (9,13\%$18,74 \%)$. Selain itu diduga juga karena selama proses perlakuan pada proses pembuatan pellet diindikasikan ada pengaruh terhadap kandungan fraksi serat yang terjadi selama pemeraman 1 hari. Menurut Astuti dkk. (2011) semakin lama pemeraman semakin menurunkan kandungan fraksi serat, hal ini diduga disebabkan oleh terurainya isi sel pada saat diperam, semakin lama diperam semakin banyak isi sel yang terurai.

Kandungan ADL yang didapat pada penelitian ini berkisar 2,25\%-6,04\% relatif sama dengan yang dilaporkan Yono dkk. (2015) pada pollard gandum terfermentasi dengan Aspergillus niger pada pakan unggas itik alabio dan mojosari terjadi penurunan perlakuan pellet juga dapat merubah komposisi kimia dan fisik dari pakan.

Selain itu diduga juga karena selama proses perlakuan pada proses pembuatan pellet diindikasikan ada pengaruh terhadap kandungan fraksi serat yang terjadi selama pemeraman 1hari. Menurut Astuti dkk. (2011) semakin lama pemeraman semakin menurunkan kandungan fraksi serat, hal ini diduga disebabkan oleh terurainya isi sel pada saat diperam, semakin lama diperam semakin banyak isi sel yang terurai.

Kandungan ADL yang didapat pada penelitian ini berkisar 2,25\%-6,04\% relatif sama dengan yang dilaporkan Yono dkk. (2002) pada pollard gandum terfermentasi dengan Aspergillus niger pada pakan unggas itik alabio dan mojosari terjadi penurunan kandungan fraksi serat yaitu ADL 3,09\%$3,95 \%$ sedangkan yang dilaporkan Maulidayanti (2015) kandungan ADL silase pelepah sawit yang ditambah biomassa indigofera (Indigofera zollingeriana) lebih tinggi yaitu $9,13 \%-18,74 \%$. 


\section{Kandungan Hemiselulosa Pellet}

Rataan kandungan hemiselulosa pellet perlakuan penelitian dapat dilihat pada Tabel 4. Hasil analisis ragam memperlihatkan perlakuan penggunaan Indigofera zollingeriana tidak signifikan terhadap perubahan kandungan hemi selulosa perlakuan penelitian. Nilai hemiselulosa yang didapat relatif sama yaitu $15,14 \%-20,98 \%$.

Hal ini mengindikasikan penggunaan Indigofera zollingeriana tidak berpengaruh terhadap kandungan hemiselulosa. Tidak terjadinya perbedaan kandungan hemi selulosa pada pakan pellet yang ditambah Indigofera zollingeriana diduga karena berhubungan dengan kandungan NDF (Tabel 4.) yang relatif juga tidak berbeda antara perlakuan. Menurut Van Soest (1994) NDF adalah zat makanan yang tidak larut dalam detergen neutral, bagian terbesar dari dinding sel tanaman yang terdiri dari selulosa, hemiselulosa, ADL dan silika.

Kandungan hemiselulosa yang didapat pada penelitian ini berkisar 15,14\%-20,98\% . Nilai ini relatif sama yang dilaporkan Yono dkk. (2002) pada pollard gandum terfermentasi dengan Aspergillus niger pada pakan unggas itik alabio dan mojosari terjadi penurunan kandungan fraksi serat yaitu hemiselulosa 13,65\%-18,07\%, sedangkan yang dilaporkan Maulidayanti (2015) kandungan NDF silase pelepah sawit yang ditambah biomassa indigofera (Indigofera zollingeriana) lebih tinggi yaitu berkisar $7,81 \%-18,20 \%$.

\section{Kandungan Selulosa Pellet}

Rataan kandungan selulosa pellet perlakuan penelitian dapat dilihat pada Tabel 4. Hasil analisis ragam memperlihatkan perlakuan penggunaan Indigofera zollingeriana tidak signifikan terhadap peningkatan kandungan selulosa perlakuan penelitian. Nilai selulosa yang didapat relatif sama yaitu $4,53 \%-8,71 \%$.

Tidak terjadinya peningkatan kandungan selulosa pellet pada semua perlakuan, hal ini diduga penggunaan Indigofera zollingeriana tidak berpengaruh terhadap peningkatan kandungan selulosa. Tidak terjadinya perbedaan kandungan selulosa pada pakan pellet yang ditambah Indigofera zollingeriana diduga karena berhubungan dengan kandungan NDF pada (Tabel4.) diikuti dengan kandungan hemiselulosa pada (Tabel 4.) yang relatif juga tidak berbeda antara perlakuan maka kandungan selulosa juga relatif sama. Pellet hasil penelitian memperlihatkan kandungan NDF yang relatif sama, sehingga akan memberikan pengaruh yang sama pada kandungan selulosa, dimana selulosa merupakan komponen yang terbesar yang ada pada NDF. Van Soest (1994) menambahkan NDF merupakan bagian terbesar dari dinding sel tanaman, terdiri dari selulosa, hemiselulosa, lignin, silika. Kandungan selulosa yang didapat pada penelitian ini berkisar 4,53\%-8,71\%. Nilai ini relatif lebih rendah yang dilaporkan Yono dkk. (2002) pada pollard gandum terfermentasi dengan Aspergillus niger pada pakan unggas itik alabio dan mojosari terjadi penurunan kandungan fraksi serat yaitu selulosa 7,18\%-9,89\% sedangkan yang dilaporkan Maulidayanti (2015) kandungan NDF silase pelepah sawit yang ditambah biomassa indigofera (Indigofera zollingeriana) lebih tinggi yaitu 10,22\%-13,51\%.

\section{KESIMPULAN DAN SARAN}

Berdasarkan hasil penelitian, dapat disimpulkan bahwa : penggunaan Indigofera zollingeriana sampai $15 \%$ dalam ransum pellet mampu menurunkan kandungan ADF dan ADL dan belum mampu menurunkan kandungan NDF serta belum mampu meningkatkan kandungan hemiselulosa dan selulosa. Penggunaan 
15\% Indigofera zollingeriana memberikan nilai terbaik terhadap kandungan fraksi serat yaitu NDF 30,39\%, ADF 9,42\%, ADL $2,25 \%$, hemiselulosa $20,98 \%$ dan selulosa $4,53 \%$.

Saran diperlukan penelitian lebih lanjut mengenai studi invivo pada ternak unggas itik.

\section{DAFTARPUSTAKA}

Abdullah L. 2010. Pengembangan pellet Indigofera sebagai sumber pakan hijauan berkualitas. Laporan Hibah Insentif. Kementrian Riset dan Teknologi.

Akbarillah. T, Kususiyah, D. Kaharuddin, dan Hidayat. 2010. Tepung Daun Indigofera sebagai Suplementasi Pakan terhadap Produksi dan Warna Yolk Puyuh (Coturnix coturnix japonica). Jurnal Sain Peternakan Indonesia 3.(1).

Astuti. T., Sari Y., dan Zulkarnaini. 2011. Pengaruh fermentasi kulit pisang dengan mikroorganisme lokal (MOL) pada lama pemeraman dan sumber MOL yang berbeda terhadap kandungan fraksi serat sebagai pakan ternak. Universitas Muara Bungo dan Politani. Padang.

Hassen, A., N.F.G. Rethman, W.A. Van Niekerk, T.J. Tjelele. 2007. Influence of season/year and specieson chemical composition andinvitro digestibility offive Indigofera accessions. Journal Anim Feed Sci Technol.136:312-322.
Ichwan, W.M. 2003. Membuat Pakan Ayam Ras Pedaging. Cet I. PT. Agromedia Pustaka. Jakarta.

Izzah U. 2011. Kualitas Fisik Pelet Daun Legum Indigofera sp. dengan Menggunakan Ukuran Pellet Die yang Berbeda dan Lama Penyimpanan. Skripsi. Institut Pertanian Bogor. Bogor.

Maulidayanti. 2015. Sifat fisik dan fraksi serat silase pelepah kelapa sawit yang ditambah biomassa indigofera (Indigofera zollingeriana). Skripsi. Fakultas Pertanian dan Peternakan. UIN SUSKA RIAU. Pekanbaru. Riau.

Svihus, B, and Zimonja, O., 2011. Chemical alterations with nutritional consequences due to pelleting animal feeds : A review. Anim. Prod. Sci. 51, 590-596.

Steel R. G. D \& J. H. Torrie. 1991. Prinsip dan Prosedur Statistika, Edisi ke-2, B Sumantri, penerjemah. Jakarta: Gramedia Pustaka Utama. Terjemahan dari: The Principle and Prosedure of Statistics.

Van Soest P. J and Goering, H. K. 1970. Forage Fiber Analyses (Apparatus, Reagents, Procedures and Some Application). Agric. Handbook 379. ARS. USDA Washington D.C.

Van Soest P. J. 1994. Nutritional Ecology of The Ruminant. 2nd Ed. Comstock Publishing Associates a Division of Cornell University Press, Ithaca and London.

Yono, C. Raharjo., T. Haryati dan Donna, G. 2002. Evaluasi Nilai Nutrisi Pollard Gandum Terfermentasi dengan Aspergillus nigerNRLL 337 pada Itik Alabio dan Itik Mojosari. Balai Penelitian Ternak. Seminar Nasional Peternakan dan Veteriner. Bogor 